\title{
Analytical evaluation and systematization of technologies for extraction of rare metals from production waste
}

\author{
L. Ya. Shubov ${ }^{1}, I$. G. Doronkina' ${ }^{2}, O . N$. Borisova ${ }^{2}, L . M$. Tyger $^{2}$, and T. R. Lyubetskaya ${ }^{3}$ \\ ${ }^{1}$ Federal State Autonomous Institution Research Institute Center for Environmental Industrial Policy, \\ Moscow, Russia \\ ${ }^{2}$ Russian State University of Tourism and Service, Moscow, Russia \\ ${ }^{3}$ Moscow State University of Food Production, Moscow, Russia
}

\begin{abstract}
The article is a message containing systematized information on resource-saving technologies as the basic for involving metalcontaining secondary raw materials in the economic turnover. The set of independent technologies arranged in a certain sequence that solve the problems of resource saving allows us to compare the specific features and effectiveness of the use of each of them, the details and features of the processes. It is shown that the following can be the main sources of rare metals and REE: phosphogypsum (REE, Sr); ash and slag waste from TPPs, ash and slag waste (REE, Ti, Sc); metallurgical slags (Ge, Be, Se, $\mathrm{Te}, \mathrm{V})$; sulfuric acid dust (Se, Te); alumina production waste - red mud (Sc, REE); liquid waste from sulphate production of titanium dioxide (Sc, $\mathrm{Ti})$; refinery dust bins (Se, Te); wastes from production of permanent magnets $(\mathrm{Nd}, \mathrm{Sm})$. It is noted that the technology uses beneficiation methods, acid leaching and ion-exchange concentration, biotechnology, electrolysis, heat treatment, a combination of different methods. To assess the quality of man-made raw materials and their suitability for complex processing and utilization, the article uses the methodology of analytical research of a set of patented technological solutions (technological samples were taken from real man-made deposits).
\end{abstract}

\section{Introduction}

Waste generated in the mining industry and metallurgy contains a large amount of nonferrous, ferrous, precious, rare metals and various types of dispersed metals. These are manmade raw materials that are stored and accumulated due to the lack of an economical and environmentally friendly technology for processing and disposal.

The rare group of metals used in relatively insignificant quantities (their content on the earth's surface is $0.53 \%$ by weight, including $0.41 \%$ is titanium): $\mathrm{Be}, \mathrm{Ga}, \mathrm{In}, \mathrm{Te}, \mathrm{Sc}, \mathrm{Y}, \mathrm{La}$, Ac, lanthanides and actinides, Ti, Zr, Hf, V, Nb, Ta, Mo, W, Po, Re, Te, elements of group I of the periodic system is conventionally referred to as rare ones.

The analysis shows that man-made mineral raw materials represent a large reserve of the country's mineral resource base. The main sources of production of rare and rare-earth metals based on use of industrial waste can be Phosphogypsum (REE, Sr); ash and slag 
waste from TPPs, ash and slag waste (REE, Ti, Sc); metallurgical slags (Ge, Be, Se, Te, V); sulfuric acid dust (Se, Te); alumina production waste - red mud (Sc, REE); liquid waste from sulphate production of titanium dioxide ( $\mathrm{Sc}, \mathrm{Ti})$; refinery dust bins ( $\mathrm{Se}, \mathrm{Te})$; wastes from the production of permanent magnets $(\mathrm{Nd}, \mathrm{Sm})[1]$.

The content of a number of useful components in production wastes allows us to consider them as substitutes for natural raw materials (in this case, production wastes often contain both rare metals and REE) [2].

A necessary condition for involvement of technogenic raw materials in the economic turnover is reliable information about its resources and quality, as well as possible directions of its processing and utilization [3-7].

The results of numerous technological tests in different directions of representative samples of industrial waste, carried out by different researchers, can be used as a method of expert assessments in determining the environmental and economic efficiency and the feasibility of involving technogenic raw materials in processing. In essence, we are talking about the study of technogenic raw materials for washability, as a result of which investment risks are minimized when recyclable materials are involved in the economic turnover.

\section{Materials and Methods}

To assess the quality of technogenic raw materials as a source of metal extraction and its suitability for complex processing and utilization, the paper uses the methodology of analytical research of a set of patented technological solutions that have novelty and usefulness.

Analysis of patented technologies:

1. The purpose of the patented technology is hydrometallurgical processing of germanium-containing slag of lead production to extract valuable components: germanium and silicon (in the form of dioxides), iron and calcium (in the form of hydroxides), zinc (in the form of salts) [8]. The composition of the slag of lead production (content, \%): silicon 11.16, germanium 0.04 , zinc 9.5 , iron 14.39 , calcium 16.52 .

2. The purpose of the patented technology is metallurgical processing of berylliumcontaining slags from the production of copper-beryllium master alloys and alloys for extraction of beryllium and copper from them [9].

A significant part of the beryllium produced in the world $(\sim 75 \%)$ is used for production of precipitation-hardening copper-based alloys that are used in high-tech industries (aerospace, electronics, etc.). Copper-beryllium alloys are characterized by high resistance to corrosion, heat and wear, hardness, tear resistance, high electrical and thermal conductivity, and non-magnetic properties. Copper-beryllium alloys are used for the manufacture of parts for radio equipment, bearings, automatic drives, chemical equipment, and automatic weapons main springs.

The widespread use of beryllium is constrained by its high price due to the complexity of the beneficiation and processing of beryllium ores. Hence, it is very important to involve beryllium-containing wastes in processing (they often contain up to $20 \%$ beryllium - many times more than it is contained in ores). Losses of beryllium and copper with slags are associated with slagging of their oxides, their partial dissolution in the slag melt, as well as entanglement of the smallest metal droplets suspended in the slag. This waste has not been processed to date, which creates economic and environmental problems (beryllium and its compounds belong to the first class of hazard).

In the Russian Federation, copper-beryllium master alloy is produced at Basalt Federal State Unitary Enterprise enterprise by direct fusion of metallic copper and beryllium. The slags formed during the smelting process are beads of copper-beryllium alloy (covered 
from the surface with a film containing beryllium oxide, mono- and divalent copper oxides and impurities that were present in the initial alloyed metals). The total content of Be in the slag is $10-20 \%$. Slag size of $90 \%+0.1 \mathrm{~mm}$ (individual pieces have a size of $20-50 \mathrm{~mm}$ ).

Waste from metallurgical production in general, and beryllium-containing wastes in particular, it is advisable to process at the source of their formation.

The developed technology is low-waste and provides for:

- melting in an induction furnace at the temperature of $1,250-1,350{ }^{\circ} \mathrm{C}$ beryllium starting slag with addition of the combined fluorine-alkaline flux using magnesium fluoride (exhaust producing metallic beryllium comprises $\mathrm{MgF}_{2} 98 \%$ ), and soda; the ratio of the components of the flux (based on the mass of the initial slag), \%: magnesium fluoride 1550, soda 5-20; the melt is kept for 15-30 minutes;

- $\quad$ separate discharge: first of the lighter secondary slag, then of the metal phase (with its use as a recycle product in the smelting of copper-beryllium alloy); metal phase yield $82 \%$ (alloy of beryllium and copper) - from the initial mass of waste; use of $\mathrm{MgF}_{2}$ makes it possible to destroy the oxide film covering the beads of metallic beryllium and copper, with the subsequent fusion of the metals;

- $\quad$ secondary slag is melted with beryllium flotation concentrates to obtain beryllium hydroxide, and then metallic beryllium.

The experiments used copper-beryllium master alloy waste of the following composition, \%: Be 12.6, Cu 86.7, Mg 0.058, Al 0.024, Fe 0.63, Pb 0.0008.

The patented technology can also be in demand at enterprises producing berylliumcontaining alloys and bronzes.

3. The purpose of the patented technology is processing of tungsten-containing ore dressing tailings using separation methods for additional extraction of $\mathrm{W}$ [10].

The content of $\mathrm{WO}_{3}$ in the tailings supplied for processing by gravity and flotation methods is $0.09 \%$, and in the resulting high-grade tungsten concentrate is $62 \% \mathrm{WO}_{3}$ (with about $50 \%$ recovery from the operation). The output of the tungsten concentrate from the operation is $0.07 \%$. The content of $\mathrm{WO}_{3}$ in the tailings is $0.04 \%$.

4. The purpose of the patented technology is to extract valuable components (aluminum, scandium, rare earth metals) from red mud (waste of alumina production) by transferring them into solution (leaching with formic $\mathrm{HCOOH}$ or acetic acid $\mathrm{CH}_{3} \mathrm{COOH}$ ) [11].

Composition of red mud, \%: $\mathrm{SiO}_{2} 9.3, \mathrm{Al}_{2} \mathrm{O}_{3} 12.4, \mathrm{Fe}_{2} \mathrm{O}_{3} 44.3, \mathrm{TiO}_{2} 4.4, \mathrm{P}_{2} \mathrm{O}_{5} 0.75$, $\mathrm{CaO} 13.6, \mathrm{MgO} 0,93, \mathrm{Na}_{2} \mathrm{O} 2.9, \mathrm{~K}_{2} \mathrm{O}$ less than 0.15, $\mathrm{V}_{2} \mathrm{O}_{5} 0.09, \mathrm{Cr}_{2} \mathrm{O}_{3} 0.05, \mathrm{MnO} 0.52$, $\mathrm{SO}_{3} 2.8$, REE (sum) 0, 14, Sc $9.0 \cdot 10^{-3}$.

The essence of the technology:

- $\quad$ acid treatment of red mud using formic or acetic acid (or mixtures thereof) as a leaching agent; leaching is carried out with the portionwise addition of red mud to the reagent solution with stirring with $\mathrm{pH}$ control (when the $\mathrm{pH}$ reaches 2.3-3.8, the addition of the mud is stopped), at the temperature of $80^{\circ} \mathrm{C}$;

- $\quad$ stirring the slurry for 1 hour after stopping the supply of sludge to the leaching process;

- keeping the suspension for 1 hour after stopping stirring (at the given temperature);

- $\quad$ separation of the solid residue from the solution by filtration (compounds of aluminum, scandium and rare earth metals pass into the solution, they are separated by known methods).

Extraction into solution under optimal conditions, \%: aluminum $\sim 63$, scandium $\sim 65$, $\mathrm{REE} \sim 50$.

5. The purpose of the patented technology is to extract scandium from red mud (waste of alumina production) using hydrometallurgy methods [12]. 
Solid phase composition of red mud, \%: $\mathrm{Fe}_{2} \mathrm{O}_{3} 46.5, \mathrm{Al}_{2} \mathrm{O}_{3}$ 12.0, $\mathrm{CaO}$ 8.0, $\mathrm{SiO}_{2}$ 10.0, $\mathrm{TiO}_{2} 4.5, \mathrm{Sc}_{2} \mathrm{O}_{3}$ 0.0130, $\mathrm{ZrO}_{2}$ 0.1. The ratio of $\mathrm{S}: \mathrm{L}$ in the pulp is 1: 4; Pulp pH 12.5.

The essence of the technology:

- repeated sequential leaching of red mud with a mixture of solutions of carbonate and sodium bicarbonate when passing through the slurry a gas-air mixture containing $\mathrm{CO}_{2}$ at the pressure of 3-6 atmg in vibro-cavitation mode; as a gas mixture can use a sintering furnace flue gases containing $8-17 \% \mathrm{CO}_{2}$ (at the pressure of 6 atmg, ${ }^{60}{ }^{\circ} \mathrm{C}$ and the process duration of 8 hours);

- two-stage holding of the productive solution; in the first step the $\mathrm{pH}$ is maintained at 9-9.5 for 3 hours at the temperature of not less than $90^{\circ} \mathrm{C}$ with further filtration (removal of impurity components);

- $\quad$ filtering the carbonized slurry to obtain a productive scandium-containing solution;

- the second stage of exposure at $\mathrm{pH} \geq 12.5$ for 3 hours at the temperature of 100 $110^{\circ} \mathrm{C}$;

- precipitation of scandium in the form of $\mathrm{Sc}_{2} \mathrm{O}_{3}$ by adding sodium hydroxide solution.

Extraction of scandium from red mud is low - only about $20 \%$. The content of $\mathrm{Sc}_{2} \mathrm{O}_{3}$ in the concentrate is $6.5 \%$.

A variety of the considered technology has been patented [13]. Its main difference: the extraction of scandium from the scandium-containing solution is carried out by sorption with phosphate ion exchangers, desorption of scandium from the organic phase of the ion exchangers is carried out with mixed carbonate-chloride solutions in a pulsating mode to obtain a scandium-containing eluate, from which stage-by-stage precipitation of poorly soluble scandium compounds is carried out. The recovery of $\mathrm{Sc}_{2} \mathrm{O}_{3}$ in the eluate is $91-94 \%$.

6. The purpose of the patented technology is disposal of aluminum slag from secondary processing of aluminum and red mud (waste of alumina production) [14].

Raw material characteristics:

- $\quad$ composition of aluminum slag, \%: $\mathrm{Al}_{2} \mathrm{O}_{3} 34, \mathrm{KCl} 22, \mathrm{NaCl} 13, \mathrm{SiO}_{2} 3.5, \mathrm{CaO}$ 1.9, $\mathrm{MgO} 4.8, \mathrm{Zn} \mathrm{0.6,} \mathrm{CuO} 0.4$, metal aluminum 11, $\mathrm{Fe}_{2} \mathrm{O}_{3}$ 2.6;

- composition of red mud (Bogoslovsky aluminum plant), \%: $\mathrm{Fe}_{2} \mathrm{O}_{3} 40, \mathrm{Al}_{2} \mathrm{O}_{3} 15$, $\mathrm{CaO} 14, \mathrm{SiO}_{2} 10, \mathrm{TiO}_{2} 4, \mathrm{Na}_{2} \mathrm{O} 4$.

The essence of the technology:

- $\quad$ grinding of aluminum slag;

- $\quad$ separation of metallic aluminum (enrichment methods);

- $\quad$ mixing the residue after the separation of metallic aluminum with red mud and sintering the material at the temperature of $800-900^{\circ} \mathrm{C}$ (combining fine-grained particles into pieces);

- separation of the oxide and salt components of the cake to isolate the salt component of aluminum oxide (the operation is carried out in an aqueous medium using an upward flow in a pulsating column operating in a closed cycle with a conical settler);

- $\quad$ returning the clarified settler solution to the column to create an upward flow;

- magnetic separation of the solid phase of the lower discharge of the pulsation column (output of the magnetic fraction $\sim 75 \%$ ).

The mixing ratio of the components aluminum slag: red mud is 1:1.5.

Directions of use of enrichment products:

- magnetic fraction - raw material for ferrous metallurgy;

- $\quad$ mixture enriched with aluminum oxide - return to alumina production;

- the amount of chlorides isolated from the solution is a flux for recycling aluminum scrap. 


\section{Results}

It is necessary to note one more source of REE - wastes from the production of permanent magnets. These wastes are not large-tonnage, but technologies for their processing began to be developed in the United States at the end of the last century; judging by the lack of publications, such works are not carried out in the Russian Federation. In accordance with the US patent, two types of wastes from the production of permanent magnets enriched with REE are identified - sawdust and slag; the technologies for extracting rare-earth elements from them are different, but they use methods of hydrometallurgy [15].

Analysis of the set of patented technological solutions proves the suitability of phosphogypsum (chemical industry), ash and slag waste (fuel and energy industry) and metallurgical waste, which form large accumulations, for reuse and reveals their wide technological capabilities as objects of processing.

It shall be emphasized that the extraction of valuable components (including metals) by itself does not solve the problem of large-tonnage waste - a low yield of useful products; their large-scale utilization can be tied to the construction industry and road construction (after the extraction of metals and, if necessary, enrichment).

The most significant developments are those that have passed large-scale tests, as well as semi-industrial and industrial approbation:

- processing of phosphogypsum with extraction of REE and radioactive elements, obtaining fertilizers and phosphate cement binder [16];

- $\quad$ extraction of rare earth metals and scandium from ash and slag waste [17];

- joint processing of cuprous slag and sludge from copper electrolyte production (extraction of rare and noble metals);

- $\quad$ extraction of vanadium compounds from metallurgical slags [18-20].

Information about these solutions shall be included in the relevant information and technical reference books, at this stage - as promising solutions that meet the modern requirements of the circular economy.

From the point of view of extraction of REE, wastes of mining and metallurgical production are of little importance, but they are serious sources for production of germanium, bismuth, scandium, titanium, beryllium, vanadium [21, 22]. In part, metallurgical slags of lead production, along with wastes from mechanical processing of sediment materials, are the main source of obtaining germanium (as well as bismuth); applied technology - hydrometallurgy. Liquid waste from titanium dioxide production is suitable for extracting not only titanium, but also scandium (extraction technology) bearing in mind that the main industrial source of scandium production is uranium ore; it is also possible to extract scandium (and REE) from red mud (waste of alumina production). A rich source of beryllium (as well as copper) are slags from the production of copperberyllium ligatures (they contain up to $20 \%$ beryllium - many times more than it is contained in ores); original thermal technologies are used to extract beryllium. The possibility of recycling dust bins of refining production is shown not only for additional extraction of precious metals, but also for obtaining a concentrate of Se and Te (the content of dust in the dust runways is 4-8 \%, Te 6-10\%). Extraction of metals into the final product is about $95 \%$ (the technology used is a combination of hydro- and pyrometallurgy).

\section{Conclusions}

Therefore, considering the quantitative characteristics of large-tonnage waste, the type and content of valuable components in them, it is possible to identify with a certain accuracy the priority directions of practical actions aimed at arranging the recycling of rare and rareearth elements: 
- $\quad$ extraction of REE from phosphogypsum;

- $\quad$ extraction of Ge and Bi from metallurgical slags;

- $\quad$ extraction of Ti and Sc from liquid titanium production wastes;

- $\quad$ extraction of Be from slags of the production of copper-beryllium alloys;

- $\quad$ extraction of $\mathrm{V}$ from metallurgical slags.

The results of assessment of patented technologies indicate that in the 21 st century, a wide range of technological solutions have been developed and tested, allowing the extraction of rare metals and REE from technogenic raw materials [23-25]. These solutions can and shall find practical application; one of the approaches may be the inclusion of information on patented technologies in the relevant information and technical reference books, at this stage - as promising solutions that meet the modern requirements of the circular economy, resource and nature management.

\section{References}

1. L. Ya. Shubov, K.D. Skobelev, S.I. Ivankov, I.G. Doronkin, Ecology of industrial production, 3(103), 15 (2018)

2. O. M. Denisyuk, Naukovy Oglyad, 5(58), 49 (2019)

3. O. N. Borisova, I. G. Doronkina, L. V. Sumzina, A. V. Maximov, M. R. Gozalova, 5th International Multidisciplinary Scientific Conference on social sciences and arts SGEM 2018. Conference proceedings, 545 (2018)

4. O. N. Borisova, I. G. Doronkina, A. V. Demenev, G. Malyutin, 5th International multidisciplinary scientific conference on social sciences and arts sgem 2018. Conference proceedings, 441 (2018)

5. H. I. Abdel-Shafy, M. S. M. Mansour, Egyptian Journal of Petroleum, 27(4), 1275 (2018)

6. O. Olubajo, O. Osha, U. El-Natafty, H. Adamu, Abubakar Tafawa Balewa University (2017)

7. V. Murko, V. Khyamyalyainen, and M. Baranova, IIIrd International Innovative Mining Symposium, E3S Web of Conferences, 41, 01042 (2018)

8. L. M. Cheremisinov, A. M. Kuraev, A. I. Demidov, RF patent No. 2423535 C22B7, C22B19, C22B41, Method of hydrometallurgical processing of mineral raw materials (2011)

9. V. E. Matyasova, A. D. Bykov, Z. M. Alekberov, G. V. Goryaev, M. L. Kotsar, RF patent No. $2558588 \mathrm{C} 22 \mathrm{C} 9, \mathrm{C} 22 \mathrm{C} 25, \mathrm{C} 22 \mathrm{C} 1, \mathrm{C} 22 \mathrm{~B} 7$, Method of processing beryllium-containing waste (2015)

10. V. A. Kantsel, A. A. Kantsel, S. A. Lapshinov, A. A. Letyushov, M. N. Fomin, V. A. Potapov, RF patent 2424333, C22B3, C22B34, Method of complex processing of tungsten-containing ore dressing tailings (2011)

11. A. V. Bogomazov, A. S. Senyuta, RF patent No. 2544725, C22B7, C22B21, C22B59, C01F7, C22B3, Method of acid processing of red mud (2015)

12. V. S. Anashkin, S. E. Vishnyakov, O. V. Petrakova, S. N. Gorbachev, A. V. Panov, RF patent No. 2562183, C22B59, C22B3, C01F17, Method of obtaining scandium concentrate from red mud (2015)

13. G. N. Klimentenok, V. S. Anashkin, S. E. Vishnyakov, A.V. Panov, RF patent No. 2536714, C22B59, C22B3, Method of obtaining scandium concentrate from red mud (2014) 
14. V. A. Nizov, D. F. Rakipov, E. V. Pustynnykh, A. R. Bakirov. RF patent No. 2540317 , C22B7, Method of processing aluminum slag (2015)

15. D. O. Skobelev, Ecological systems and devices, 12, 29 (2018)

16. D. O. Skobelev, Ecological systems and devices, 1, 12 (2019)

17. I. Kotarska, B. Misera, P. Stefanek, E3S Web of Conferences 41, III International Innovative Mining Symposium, 02013 (2018)

18. M. Samir, F. Alama, P. Buiss, T. van Nylen, O. Ostanin, III International Innovative Mining Symposium. E3S Web of Conferences 41, 02012 (2018)

19. A. Pinchuk, N. Tkalenko, V. Markhasova, IV-th International Innovative Mining Symposium. E3S Web of Conferences 105, 04048 (2019)

20. J. Pyssa, E3S Web of Conferences 14, 02024 (2017)

21. V. Mymrin, K. Alekseev, O. M. Fortini, Y. K. Aibuldinov, C. L. Pedroso, A. Nagalli et al, Journal of Cleaner Production, 161, 376 (2017)

22. B. Greenberg, US patent No. 5429724, C25C1, Neodymium recovery process (1995)

23. M. A. Konov, R. Kh. Khamizov, RF patent No. 2630072 C22B59, Method of ensuring environmental safety of industrial waste in the form of phosphogypsum with obtaining a two-component target product (2017)

24. T. V. Vlasova, N. S. Velichkina, A. V. Kalashnikov, A. A. Zakharov, P. Yu. Novikov, V. Yu. Koltsov, M. E. Zvonareva, T. B. Yudina, RF No. 2630072, C22B59, 2016 / RF patent No. 2657149 C22B, Method for extracting rare earth metals and scandium from ash and slag waste (2018)

25. N. F. Danilov, V. V. Vdovin, A. A. Karpov, A. A. Kamenskikh, V. P. Kudryashov, RF patent No. 2230128 C22B34, Method of processing vanadium-containing converter slags (2015) 